Meaningful Living, Resilience, Affective Balance, and Psychological Health Problems during COVID-19

\author{
Gökmen Arslan \\ Mehmet Akif Ersoy University \\ Murat Yıldırım \\ University of Leicester \\ Paul T. P. Wong \\ Trent University
}

Author Note

Corresponding Author: Gökmen Arslan, Ph. D., Department of Psychological

Counseling and Guidance, Faculty of Education, Mehmet Akif Ersoy University in Burdur, Turkey. E-mail: gkmnarslan@gmail.com.tr 


\begin{abstract}
The present study sought to investigate the mediating effect of the affective balance and resilience on the association between meaningful living and psychological health problems among Turkish young adults in the context of pandemic. Participants were 359 Turkish young adults, comprising of primarily female (68.2\%), and their age ranged between 18 to 43 (age $M$ $=20.67, S D=3.62)$. Findings from this study indicated that meaningful living had a positive predictive effect on resilience and positive affect, as well as a negative predicative on psychological health challenges and negative affect. Resilience and affective balance also mediated the effect of meaningful living on psychological health of young adults. These results suggest that resilience and affective balance are important aspects of implementing meaning-based preventions and interventions. Thus, meaning-based prevention and intervention strategies could be designed to not only to improve individuals' life meaning and purpose but also build up resilience and positive affective experiences to foster their psychological health.
\end{abstract}

Keywords. Meaningful living, resilience, affect, psychological health, positive psychology 


\section{Meaningful Living, Resilience, Affective Balance, and Psychological Health Problems during COVID-19}

On March 11, 2020, the World Health Organization (WHO) declared COVID-19 as a pandemic caused by a novel coronavirus SARS-CoV2 (WHO, 2020a). Within few months, the world has been adversely affected by the rapid escalation of the virus, exponential growth in the number of new cases and fatality rate of the COVID-19 (Wu et al., 2020; Zhou et al., 2020). According to daily statistics published by Johns Hopkins University, as of 9 May 2020, there have been more than 3,9 million confirmed COVID-19 cases worldwide and more than 275,000 deaths, affecting 187 countries and territories (Center for Systems Science and Engineering, 2020).

Continuous dangers from COVID-19 and disruptions of everyday life have undoubtedly caused serious psychosocial consequences. During the outbreak, prevalence of mental health problems has increased substantially, especially among those with pre-existing psychiatric symptoms, and further worsening their daily functioning and cognition (Yang et al., 2020). Maintaining psychological health can be difficult with the presence of psychological distress (e.g., anxiety and depression) (de Cates, Stranges, Blake, \& Weich, 2015); therefore, it is just as important to protect individuals' mental health and psychosocial well-being during outbreak as maintaining physical health (WHO, 2020b). It has been demonstrated that individuals' resources, competencies, and psychological strengths, such as positive emotions (e.g., happiness), positive individuals' traits (e.g., resilience), and socialenvironmental factors (e.g., supportive relationship) can protect mental health and reduce the risk of diseases (Kobau et al., 2011; Yildirim, \& Arslan, 2020). Using an existential positive psychology perspective, this study therefore aims to examine the associations between meaningful living, resilience, affective balance, and psychological health during COVID-19 pandemic. 


\section{Meaningful Living and Psychological Health}

In the face of adversity, people are more likely to lose a sense of meaning of life, feel disenchanted, and disengaged which could have adverse effects on their psychological health (Frankl, 1985; Hicks \& Routledge, 2013; Batthyany \& Russo-Netzer, 2014). Having a sense of meaning in life can play a key role to sustain and maintain psychological health of those who suffer from problems. Meaningful living has become a central topic in existential positive psychology (PP2.0; Wong, 2010, 2020) which is characterised by a balanced understanding of the good life, incorporating the dynamic interaction between positives and negatives, meaning-cantered, and culture). According to the existential model, there are two key elements of meaning (i) the cognitive aspect of making sense and reappraising life events, and (ii) the existential aspect of searching out purpose and meaning for one's existence and future (Wong, 1998). He has found seven major sources of meaning in life: (a) achievement, (b) acceptance, (c) relationship, (d) intimacy, (e) religion, (f) self-transcendence, and (g) fair treatment. These pathways are important in terms of producing a road map for those who struggle to find a new purpose of life for the future (Wong, 1998).

Psychological distress is characterized as a general, dysfunctional psychological functioning in the face of adversity (Abeloff, Armitage, Niederhuber, Kastan, \& McKenna, 2004). High levels of psychological distress can lead to serious psychological health problems which may need treatment (Weissman, Pratt, Miller, \& Parker,2015). The degree of psychological distress can vary from people to people. During a pandemic, there is a wide array of psychosocial and socioeconomic factors affecting the experience of psychological distress among people, such as amount of exposure to negative contents in media, social support, subjective experience of COVID-19, and length of isolation (Zhang et al., 2020).

Studies have demonstrated that meaningful living and psychological health is closely associated with each other. Research using existential-based approach reported that 
meaningful living can predict hope and depressive symptoms uniquely and prospectively (Mascaro, \& Rosen, 2005). Meaningful living can also assist victims to overcome abuse and post-traumatic stress disorder and promote their well-being by helping them to move beyond not only to survive but also a new level of resilience and vitality (Wong, \& McDonald, 2002). Furthermore, Jans-Beken and Wong (2019) highlighted that having a sense of existential gratitude is beneficial for individuals with a trauma history. Previous research has also showed that individuals with high levels of meaningful life have higher levels of subjective well-being, psychological well-being, quality of life, and optimism (Ho, Cheung, \& Cheung, 2010), self-efficacy (DeWitz, Woolsey, \& Walsh, 2009), self-esteem (Schlegel, Hicks, King, \& Arndt, 2011), and adaptive coping strategies (Edwards \& Holden, 2001) and lower levels of psychological distress such as anxiety and depression (Korte, Cappeliez, Bohlmeijer, \& Westerhof, 2012), stress (Bauer-Wu \& Farran, 2005), and suicidal thoughts (Edwards \& Holden, 2001).

Within the context of pandemic, studies demonstrated that patients, who were diagnosed with COVID-19, experienced high prevalence of depression (29.2\%) and anxiety (21.1\%). A high level of anxiety (22.4\%) among general public was also reported (Zhang et al., 2020). Similar results have been reported in another study comparing four groups of people -patients with COVID-19, medical students, medical workers, and general populationin the degrees of self-reported mental health problems. In that study, although high levels of psychological distress were observed among four groups of people, medical students and patients diagnosed with COVID-19 were at the high risk of developing some mental health problems by reporting higher levels of stress, anxiety and depression compared to their counterparts (Ashtari et al., 2020). This is alarming and requires an urgent need for investigating psychological distress during pandemic. Meaningful living can function as a factor in protecting psychological health of individuals during pandemic. 


\section{Meaningful Living, Affect Balance and Resilience}

Meaningful living is an important capacity that can foster resilience and well-being (Oliver, Collin, Burns, \& Nicholas, 2006; Wong, 2012). Well-being is generally measured by subjective well-being, defined as comprising affective and cognitive evaluations of one's life (Diener, Lucas, \& Oishi, 2018). The affective component refers to evaluation of the emotions that individuals experience in their day-to-day lives, such as, feel good, upset, nervous, afraid, excited, attentive, and proud (Watson, Clark, \& Tellegen, 1988). Affect balance is conceptualized as predominance of positive affect over negative affect (Diener et al., 2018). Affect balance contributes to life satisfaction (Diener \& Larsen, 1993). Cognitive component (satisfaction with life) refers to a judgment process that people evaluate their life as a whole as satisfactory (Diener, Emmons, Larsen, \& Griffin, 1985). Positive emotions facilitate the ability of problem solving by creating many possible solutions to problems and in turn this increased coping ability can predict experience of positive emotions in future. With this continuous cycle, individuals can develop their psychological resilience and increase their emotional well-being and psychological health (Fredrickson, \& Joiner, 2002). In a study, researchers demonstrated that affect balance exerted a direct effect on life satisfaction and mediated the relationship between resilience and life satisfaction (Liu, Wang, \& Lü, 2013).

Resilience has been a topic of interests within the burgeoning literature of human strengths. Resilience is a salient psychological strength that can reduce detrimental effect of stressors on psychological health. The concept of resilience has been identified as an ability to cope and adapt effectively in response to major stressors (Luthar, 2003; Luthar, Cicchetti, \& Becker, 2000). Resilience has also been conceptualized as a critical psychological resource that refers to the ability of "bounce back" from stress quickly, adapt to new situation flexibly and even positive psychological change in the face of the adversity settings (Bonanno, 2004). Research showed that resilience can pioneer many successful outcomes in human functioning. 
For example, studies have highlighted that resilience can function as a protective factor under stressful conditions, by diminishing potential risk associated with adjustment problems and heightening probability of positive psychological outcomes (Tedeschi, \& Kilmer, 2005).

\section{Affective Balance, Resilience, and Psychological Health}

The impact of positive emotions on resilience and psychological health has been studied in previous research, suggesting that positive emotions has a direct effect on resilience and psychological health. Resilience was also found to have a direct effect on psychological health (Gloria, \& Steinhardt, 2016). Furthermore, research shows that affect balance is associated with a wide range of factors including meaningful living (Ho et al., 2010; Steger et al., 2006; Steger, Oishi, et al., 2009; Yalçın \& Malkoç, 2015), health-related quality of life (Moon, Yoon, Jeong, \& Cho, 2018), daily emotional experiences (Veilleux et al., 2020), depressive symptoms (Pieruccini-Faria, Muir-Hunter, \& Montero-Odasso, 2018), personal well-being and social capital (Veronese, Pepe, Dagdukee, \& Yaghi, 2018), and self-esteem (Liang, Xu, Xia, \& Ma, 2020). With regards to resilience, growing literature demonstrates that resilience is a significant predictor of meaningful living (Kleiman, \& Beaver, 2013), psychological distress, subjective well-being, and quality of life (Tecson, Wilkinson, Smith, \& Ko, 2019), affect balance, life satisfaction, and psychosocial well-being, and decreased negative affect (Yildirim, 2019), moods, depression, and anxiety (Burns, Anstey, \& Windsor, 2011). Furthermore, resilience mediates the relationship affect balance and cognitive impairment (Xie, Zhou, Deng, Richmond, \& Na, 2019). Within the context of COVID-19, a recent study showed that resilience had a significant direct effect on subjective well-being and psychological health among general public during early phase of COVID-19 (Yildirim, \& Arslan, 2020). Collectively, evidence shows that psychological resilience and positive emotions can buffer the negative impacts of psychological distress such as stress and negative 
affect (Ong, Bergeman, Bisconti, \& Wallace, 2006). These findings suggest that resilience is associated with positive mental health outcomes.

\section{Present study}

Given that psychological health and wellbeing are utmost importance during pandemic, this study aimed to examine the impact of meaningful living, affect balance, and resilience on psychological health. Based on the preceding rationale and extant literature, we hypothesized that (i) meaningful living would have a direct effect on positive affect, negative affect, resilience, and psychological health, (ii) positive affect and negative affect would have direct effect on resilience and psychological health, (iii) resilience would have a direct effect on psychological health, (iv) positive affect and negative affect would mediate the relationship between meaningful life and resilience and psychological health, (v) resilience would mediate the relationship between meaningful life and psychological health, and (vi) resilience would mediate the relationship between positive affect and negative affect and psychological health.

\section{Method}

\section{Participants}

Participants were 359 Turkish young adults, comprising of primarily female (68.2\%), and their age ranged between 18 to 43 years (age $M=20.67, S D=3.62$ ). With regards to adults' coronavirus experiences, $68.2 \%$ were in quarantine and two participants were also infected. Other participants reported that they self-isolated themselves. An online survey portal was created using demographic items and the measures of the study. Institutional review board approval was obtained before data collection process, and the participants were informed that participation in the study was voluntary, the survey was confidential, and they could quit the survey at any time if they did not want to continue. Prior to data collection 
process, an electronic assent form was signed by adults who volunteered to participate in the study.

\section{Measures}

Meaningful Living. Meaningful living was measured using Meaningful Living Measure (MLM; Arslan, 2020) that is a 6-item self-report scale (e.g., "As a whole, I find my life meaningful"). All items of the scale are scored using a 7-point Likert type scale ranging from strongly disagree (1) to strongly agree (7). Previous research has revealed that the MLM had strong internal reliability estimates with Turkish sample (Arslan, 2020). Findings of this study indicated that the scale provided a strong internal reliability estimate with the present sample, see Table 1.

Psychological Health Problems. Brief Symptom Inventory (BSI-18) was used to measure adults' psychological health problems (Derogatis \& Fitzpatrick, 2004). The scale is an 18-item self-report survey, comprising of six-item subscales: depression, anxiety, and somatization (e.g., "Feeling no interest in things", "Pains in heart or chest"). All items of the scale are responded using a 5-point Likert type scale, ranging from not at all (0) to very much (4). Previous research indicated that the scale and its subscales had strong internal reliability estimates for Turkish university adults (Arslan, 2020). In the present study, the results indicated that the scale had a strong internal reliability estimate, see Table 1.

Resilience. Brief Resilience Scale (BRS) was used to measure resilience as bouncing back from negative life experiences (Smith et al., 2008). The BTS is a 6-item self-report measure (e.g., "I tend to bounce back quickly after hard times), scoring all items of it using a 5-point Likert scale ranging between strongly disagree (1) and strongly agree (5). Previous research provided evidence supporting that the scale had strong internal reliability estimate with Turkish sample (Doğan, 2015). The scale also had a strong internal reliability estimate with the present sample, see Table 1. 
Affective Balance. Scale of Positive and Negative Experience (SPANE) (Diener et al., 2010) were combined to measure individuals' subjective well-being. The SPANE is a $12-$ item self-report questionnaire used to assess individuals' emotions and moods and includes two six-item subscales: Positive Feelings Scale (PAS; e.g., "Pleasant", "Good") and Negative Affect Scale (NAS; e.g., "Unpleasant", "Negative"). All items of the scale are rated on a 5point Likert scale, ranging from very rarely or never (1) to 'very often or always (5). Research indicated that the scale had good psychometric properties and strong internal reliability estimates for Turkish samples (Telef, 2013). Internal reliability estimates of the scale were adequate-strong with the present sample, Table 1.

\section{Data analyses}

Preliminary analyses were first conducted to examine descriptive statistics (e.g., mean, standard deviation), the normality assumption and internal reliability estimates of the variables. Subsequently, Pearson product-moment correlation analysis was performed to investigate the associations between meaningful living, positive and negative affect, resilience, and psychological health. Normality assumption was investigated using kurtosis and skewness scores and their cut-off values and their scores lower than $|2|$ is an acceptable range for being normally distributed (D’Agostino, Belanger, \& D’Agostino, 1990; Field, 2009). Second, we conducted a mediation model to analyze the mediating role of affective balance and resilience in association between meaningful living and psychological health using the PROCESS macro (Model 80) for SPSS version 3.4 (Hayes, 2018). Findings from this analysis were interpreted using standardized regression estimate $(\beta)$ scores and squaredmultiple correlations $\left(R^{2}\right)$, with traditional effect sizes:.01-.059 $=$ small, $.06-.139=$ moderate, and $\geq .14=$ large (Cohen, 1988). Moreover, the bootstrapping method with 10000 resamples to estimate the $95 \%$ confidence intervals (CI) was conducted to examine the significance of indirect effects (Hayes, 2018; Preacher \& Hayes, 2008). The bootstrapping approach is 
specified to be a significantly more effective method than other methods, especially for research with a relatively smaller sample size (Hayes, 2009; Preacher \& Hayes, 2008). Therefore, we examined bias-corrected bootstrapping procedures to test the mediation model. All analyses were conducted using SPSS version 25.

\section{Results}

\section{Preliminary Analysis}

Findings from preliminary analysis indicated that kurtosis values were between -1.14 and .73 , and skewness scores ranged from -1.44 and .13 , and these scores suggested that all variables had relatively normal distribution (skewness and kurtosis values $<|2|$ ). The internal reliability estimates of the scales were investigating showing that the scales had adequate-tostrong internal reliability coefficients (range $\alpha=.77$ to .92 ), as shown in Table 1 . We investigated the univariate and multivariate outliers using $z$-scores $(z \pm 4)$ and Mahalanobis distance, and three outliers was excluded from the analyses (Stevens, 2009; Tabachnick \& Fidell, 2013).

Subsequently, findings from correlation analysis showed that meaningful living was positively and moderately associated with positive feelings $(r=.41, p<.001)$ and resilience $(r=$ $.29, p<.001)$, as well as had negative and small-moderate correlations with negative affect ( $r=$ $-.22, p<.001)$ and psychological health problems $(r=-.42, p<.001)$. Positive affect was positively and moderately related to resilience $(r=.37, p<.001)$ and negatively and moderately correlated with psychological health problems $(r=-.35, p<.001)$. There was a positive and moderate correlation between negative feelings and psychological health problems $(r=.43$, $p<.001$ ), and negative feelings was also negatively and moderately correlated with resilience $(r=-.38, p<.001)$, as shown in Table 1 . 


\section{Mediation Analyses}

After examining the preliminary analyses, the mediation model was conducted to examine the direct and indirect relationships between variables. Findings from the mediation analysis firstly revealed that meaningful living significantly predicted positive $(\beta=.41, p<$ $.001)$ and negative affect $(\beta=-.21, p<.001)$, accounting for $17 \%$ of the variance in positive feelings and for $5 \%$ of the variance in negative affect. Meaningful living also had a direct and significant predictive effect on resilience $(\beta=.15, p<.05)$ and predicted resilience through positive $(\beta=.23, p<.001)$ and negative feelings $(\beta=-.25, p<.001)$ significantly. Meaningful living and affective balance components together accounted for $21 \%$ of the variance in resilience, as shown in see Table 2 and Figure 1. These results suggest that affective balance, namely positive and negative feelings, has a mediation effect in the association of meaningful living with resilience.

Next, the results showed that meaningful living had significant predictive effect on psychological health problems $(\beta=-.28, p<.001)$. psychological health was also significantly predicted by negative affect $(\beta=.27, p<.001)$ and resilience $(\beta=-.17, p<$ $.001)$, but positive feelings did not directly predict psychological health $(\beta=-.08, p=.13)$. all variables together accounted for $32 \%$ of the variance in psychological health problems. These results provide evidence indicating that meaningful living predict psychological health through resilience and affective balance. Resilience also partially mediates the association of negative feelings with psychological health while has a full mediation effect in the relationship between positive affect and psychological health, as shown in Table 2 and Figure 1. The indirect effects of meaningful living on psychological health through mediators was significant. Unstandardized total, direct and indirect effects, and 95\% bias-corrected confidence interval predicting psychological health scores are presented in Table 3. 


\section{Discussion}

The present study sought to investigate the mediating effect of the affective balance and resilience on the association between meaningful living and psychological health problems among Turkish young adults in the context of pandemic. Findings from this study revealed that meaningful living had a significant predictive effect on affective balance components, including positive and negative affect. Specifically, meaningful living more strongly predicted positive affectivity compared with negative affectivity and was also a significant and negative predictor of psychological health problems of adults. The results of this study are consistent with previous evidence indicating the association between meaningful living and affective balance (Ho et al., 2010; Steger, Frazier, Oishi, \& Kaler, 2006; Steger, Oishi, et al., 2009; Yalçın \& Malkoç, 2015) and psychological health indicators, such as depression, anxiety, somatization, and alienation (Bauer-Wu \& Farran, 2005; Brassai et al., 2011; Du et al., 2017; Ho et al., 2010; Korte et al., 2012; Steger et al., 2006; Steger, Mann, et al., 2009). For example, Steger, Oishi, et al. (2009) reported that meaning in life was associated with a variety of well-being and psychological health indicators (e.g., life satisfaction, positive affect, happiness, and depression) at all life stages. Given the existential positive psychology framework, meaning is a key to psychological health and flourishing of individuals (Frankl, 1985; Wong, 2016), and meaningful living help individuals to overcome psychological challenges and foster their well-being by helping them to move beyond not only to survive but also a new level of resilience and vitality (Wong, \& McDonald, 2002). Reker and Wong (1988) emphasized that "the realization of personal meaning is always accompanied by feelings of satisfaction and fulfilment" (p. 221). Therefore, meaningful experiences may lead to more positive affective experiences and promote psychological health and well-being. Within this theoretical and empirical context, the sense of meaning in life might facilitate the experience of positive affectivity and contribute to promoting the 
psychological health of individuals. Hereby, these results suggest that individuals with high levels of meaningful living have higher levels of positive affect, as well as lower levels of negative affect and psychological health challenges.

Results from the current study further showed that positive and negative affect significantly predicted resilience and mediated the effect of meaningful living on this construct. In addition to supporting the association between meaningful living and positive affect (Pan et al., 2008; Yalçın \& Malkoç, 2015), these results indicate the importance of affective balance in building and promoting resilience among young adults. Affective balance is a construct referring to the balance between negative and positive affect (Diener et al., 2018), and the frequency and intensity of the positive and negative feelings of individual (Reis \& Hoppe 2015). According to broaden-and-build theory (Fredrickson, 2001; 2005), positive emotions widen human cognition and stimulate people to think more freely, creatively, and thoughtfully, which in turn help them to find a positive meaning within adversity and view the world with a wider perspective. As a consequence of this, individuals who experience high levels of positive emotions have an ability to produce various possible coping strategies in the face of adversity (Fredrickson, \& Joiner, 2002). Consistent with the outcomes of this study, previous research indicated that affect balance was associated with a variety of quality of life and psychological health outcomes, including depressive symptoms, resilience, and self-esteem (Arslan, 2015a; Karaırmak \& Siviş-Çetinkaya, 2011; Kelle \& Uysal Irak, 2018; Liang et al., 2020; Pieruccini-Faria et al., 2018; Veronese et al., 2018). For example, Arslan (2015b) found a large predictive effect of positive affectivity on resilience, and positive affect was reported as an important source in the building of resilience in adolescence to adulthood (Arslan, 2016; Tugade \& Fredrickson, 2004). Positive feelings may contribute to people's cognitions and behaviours to build their psychological and social 
resources, and; thereby, resilient individuals are more likely to report positive emotions even when experience adversity (Strand et al., 2006; Tugade \& Fredrickson, 2004).

As importantly, findings of the study revealed that resilience fully mediated the association between positive affect and psychological health, while partially mitigated the effect of negative affect on psychological health of adults. Moreover, resilience partially mediated the effect of meaningful living on psychological health. Resilience is an important psychological strength to improve well-being and address the psychological health (Arslan, 2019; Luthar, 2003; Luthar, Cicchetti, \& Becker, 2000; Bonanno, 2004). Findings from this study are consistent with literature supporting the association between affective balance, resilience, and psychological health (Arslan, 2015; Du et al., 2017; Karaırmak \& SivişÇetinkaya, 2011; Kim et al., 2005; Tugade \& Fredrickson, 2004; Wong \& Wong, 2012). Meaning was both empirically and theoretically emphasized as an important resource for resilience (Wong \& Wong, 2012), and the sense of meaningful life help people to bounce back in the face of challenges by providing personal resources and adaptive flexibility. Frankl (1985) highlighted that all individuals have the will to meaning, which in turn contributes to overcoming challenges in order to have meaningful living. Additionally, findings of the study revealed that resilience mediated the effect of meaningful living and affective balance on psychological health among young adults. Consistent with these results, previous research indicated the mediating effect of resilience on psychological health problems in the context of various adverse experiences (e.g., child maltreatment, social exclusion, and stress; Arslan, 2016, 2019; Karaırmak \& Siviş-Çetinkaya, 2011; Lee et al., 2018; Shi et al., 2015). A metaanalysis study by Hu et al. (2015) revealed that individuals with lower resilience reported greater depression, negative affect, and anxiety, as well as lower positive affect and life satisfaction than those with higher resilience. Similar to finding of this study, Loh et al. (2014) reported that resilience partially mitigated the effect of negative emotions on 
depressive symptoms while fully mediated the association between positive affect and depressive symptoms. Within the context of COVID-19, a recent study showed that resilience had a significant direct effect on subjective well-being and psychological health among general public during early phase of COVID-19 (Yildirim, \& Arslan, 2020). Individuals with high resilience are able to use more flexible strategies and to have an ability to self-regulate themselves in the face of adverse events (Loh et al., 2014; Tugade \& Fredrickson, 2004). Therefore, they are more likely to report fewer psychological health challenges compared with those with lower resilience.

\section{Conclusion and Limitations}

Findings from this study indicated that meaningful living has a positive predictive effect on resilience and positive affect, as well as a negative predicative on psychological health challenges and negative affect. Resilience and affective balance also mediate the effect of meaningful living on psychological health of young adults. These results suggest that resilience and affective balance are important aspects of implementing meaning-based preventions and interventions. Thus, meaning-based prevention and intervention strategies could be designed to not only to improve individuals' life meaning and purpose but also build up resilience and positive affective experiences to foster their psychological health. Additionally, given the importance of meaning in the coping process of adverse experiences (e.g., coronavirus pandemic), mental health providers could use meaning-based strategies to foster the promotion of mental health and reduce the risk of psychological challenges. JansBeken and Wong (2019) emphasized that mental health providers can use meaning-based approach to support individuals to benefits from adversities, and to strive for finding a meaning in the negative events that that happened to them. Further, this study supports that positive affect is key to promote the resilience and psychological health of adults. Thus, positive emotions may be integrated with the meaning approach to improve well-being and 
psychological health. This approach could facilitate individuals to deal with stressors such as coronavirus pandemic by promoting their resilience resources. Focusing aspects of meaningpreventions and interventions on harnessing positive emotions to improve resilience may cause even greater reductions in psychological health problems

Although the present study has provided important implication for research and practice, the study was designed using the cross-sectional approach which cannot ascertain a causal relationship among the study variables. Therefore, further studies using longitudinal designs are warranted to offer additional insights into the associations between the variables of the study. Subsequently, self-reported measures are considered another limitation of this study, and future research should use multiple techniques (e.g., qualitative and quantitative) for the investigation of the relationship between the study variables. Given the characteristics of the sample in the present study, future research could be conducted using different samples to investigate the associations that were found in this study. Lastly, future studies could examine different models including other life outcomes, such as flourishing that might also be mediated by the resilience and affective components. 


\section{References}

Abeloff, M. D., Armitage, J. O., Niederhuber, J. E., Kastan, M. B., \& McKenna, W. G. (2004). Review of Clinical Oncology. Philadelphia: Churchill Livingstone.

Arslan, G. (2015). Ergenlerde psikolojik sağlamlık: Bireysel koruyucu faktörlerin rolü. Türk Psikolojik Danışma ve Rehberlik Dergisi, 5(44), 73-82.

Arslan, G. (2016). Psychological maltreatment, emotional and behavioral problems in adolescents: The mediating role of resilience and self-esteem. Child Abuse and Neglect, 52, 200-209. https://doi.org/10.1016/j.chiabu.2015.09.010

Arslan, G. (2019). Mediating role of the self-esteem and resilience in the association between social exclusion and life satisfaction among adolescents. Personality and Individual Differences, 151, 109514. https://doi.org/10.1016/j.paid.2019.109514

Arslan, G. (2015). Çocuk ve Genç Psikolojik Sağlamlık Ölçeği'nin (ÇGPSÖ) psikometrik özellikleri: Geçerlilik ve güvenirlik çalışması. Ege Eğitim Dergisi, 16(1), 1-12.

Ashtari, S., Vahedian-Azimi, A., Moayed, M. S., Rahimibashar, F., Shojaei, S., \& Pourhoseingholi, M. A. (2020). Compare the severity of psychological distress among four groups of Iranian society in COVID-19 pandemic. Doi: 10.21203/rs.3.rs$23828 / \mathrm{v} 1$

Bauer-Wu, S., \& Farran, C. J. (2005). Meaning in life and psycho-spiritual functioning: A comparison of breast cancer survivor and healthy women. Journal of Holistic Nursing, 23(2), 172-190.

Bonanno, G. A. (2004). Loss, trauma, and human resilience. American Psychologist, 59, 2028.

Brassai, L., Piko, B. F., \& Steger, M. F. (2011). Meaning in Life: Is It a Protective Factor for Adolescents' Psychological Health? International Journal of Behavioral Medicine, 18(1), 44-51. https://doi.org/10.1007/s12529-010-9089-6 
Burns, R. A., Anstey, K. J., \& Windsor, T. D. (2011). Subjective well-being mediates the effects of resilience and mastery on depression and anxiety in a large community sample of young and middle-aged adults. Australian and New Zealand Journal of Psychiatry, 45(3), 240-248.

Center for Systems Science and Engineering. (2020). Coronavirus COVID-19 global cases at Johns Hopkins University. Retrieved from https://coronavirus.jhu.edu/map.html

Cohen, J. (1988). Statistical power analysis for the behavioural sciences (2nd ed.). Hillsdale, NJ: Lawrence Erlbaum.

D’Agostino, R. B., Belanger, A., \& D’Agostino, R. B. (1990). A Suggestion for Using Powerful and Informative Tests of Normality. The American Statistician, 44(4), 316. doi: $10.2307 / 2684359$

de Cates, A., Stranges, S., Blake, A., \& Weich, S. (2015). Mental well-being: an important outcome for mental health services? The British Journal of Psychiatry, 207(3), 195197.

Derogatis, L. R., \& Fitzpatrick, M. (2004). The SCL-90-R, the Brief Symptom Inventory (BSI), and the BSI-18. In M. E. Maruish (Ed.), The use of psychological testing for treatment planning and outcomes assessment: Instruments for adults, Volume 3, 3rd ed. (pp. 1-41). Mahwah, NJ, US: Lawrence Erlbaum Associates Publishers.

DeWitz, S. J., Woolsey, M. L., \& Walsh, W. B. (2009). College student retention: An exploration of the relationship between self-efficacy beliefs and purpose in life among college students. Journal of College Student Development, 50(1), 19-34.

Diener, E. D., Emmons, R. A., Larsen, R. J., \& Griffin, S. (1985). The satisfaction with life scale. Journal of Personality Assessment, 49(1), 71-75.

Diener, E., \& Larsen, R.J. (1993). The experience of emotional well-being. In M. Lewis \& J.M. Haviland (Eds.), Handbook of emotions (pp. 405-415). New York: Guilford. 
Diener, E., Lucas, R. E., \& Oishi, S. (2018). Advances and open questions in the science of subjective well-being. Collabra Psychology, 4(1):15. Doi: 10.1525/collabra.115

Diener, E., Wirtz, D., Tov, W., Kim-Prieto, C., Choi, D., Oishi, S., \& Biswas-Diener, R. (2010). New Well-being Measures: Short Scales to Assess Flourishing and Positive and Negative Feelings. Social Indicators Research, 97(2), 143-156. doi: 10.1007/s11205-009-9493-y

Doğan, T. (2015). Kısa Psikolojik Sağlamlık Ölçeği'nin Türkçe uyarlaması: Geçerlik ve güvenirlik çalışması. The Journal of Happiness \& Well-Being, 3(1), 93-102.

Du, H., Li, X., Chi, P., Zhao, J., \& Zhao, G. (2017). Meaning in life, resilience, and psychological well-being among children affected by parental HIV. AIDS Care, 29(11), 1410-1416. https://doi.org/10.1080/09540121.2017.1307923

Edwards, M. J., \& Holden, R. R. (2001). Coping, meaning in life and suicidal manifestations examining gender differences. Journal of Clinical Psychology, 57(12), 1517-1534.

Field, A. (2009). Discovering statistics using SPSS. London: Sage publications.

Frankl, V. E. (1985). Man's search for meaning. Simon and Schuster.

Fredrickson, B. L., \& Joiner, T. (2002). Positive emotions trigger upward spirals toward emotional well-being. Psychological Science, 13(2), 172-175.

Gloria, C. T., \& Steinhardt, M. A. (2016). Relationships among positive emotions, coping, resilience and mental health. Stress and Health, 32(2), 145-156.

Hayes, A. F. (2009). Beyond Baron and Kenny: Statistical Mediation Analysis in the New Millennium. Communication Monographs, 76(4), 408-420.

Hayes, A. F. (2018). Introduction to mediation, moderation, and conditional process analysis: A regression-based approach. New York: Guilford Press.

Ho, M. Y., Cheung, F. M., \& Cheung, S. F. (2010). The role of meaning in life and optimism in promoting well-being. Personality and Individual Differences, 48(1), 658-663. 
Hu, T., Zhang, D., \& Wang, J. (2015). A meta-analysis of the trait resilience and mental health. Personality and Individual Differences, 76, 18-27. https://doi.org/10.1016/j.paid.2014.11.039

Jans-Beken, L., \& Wong, P. T. (2019). Development and preliminary validation of the Existential Gratitude Scale (EGS). Counselling Psychology Quarterly, 1-15.

Karaırmak, Ö., \& Siviş-Çetinkaya, R. (2011). Benlik saygısının ve denetim odağının psikolojik sağlamlık üzerine etkisi: duyguların aracı rolü. Türk Psikolojik Danışma ve Rehberlik Dergisi, 4(35), 30-43. https://doi.org/10.17066/pdrd.81376

Kim, T.-H., Lee, S. M., Yu, K., Lee, S., \& Puig, A. (2005). Hope and the meaning of life as influences on Korean adolescents' resilience: Implications for counselors. Asia Pacific Education Review, 6(2), 143-152. https://doi.org/10.1007/BF03026782

Kleiman, E. M., \& Beaver, J. K. (2013). A meaningful life is worth living: Meaning in life as a suicide resiliency factor. Psychiatry Research, 210(3), 934-939.

Kobau, R., Seligman, M. E., Peterson, C., Diener, E., Zack, M. M., Chapman, D., \& Thompson, W. (2011). Mental health promotion in public health: Perspectives and strategies from positive psychology. American Journal of Public Health, 101(8), e1e9.

Korte, J., Cappeliez, P., Bohlmeijer, E. T., \& Westerhof, G. J. (2012). Meaning in life and mastery mediate the relationship of negative reminiscence with psychological distress among older adults with mild to moderate depressive symptoms. European Journal of Ageing, 9(4), 343-351.

Lee, S. W., Bae, G. Y., Rim, H. D., Lee, S. J., Chang, S. M., Kim, B. S., \& Won, S. (2018). Mediating effect of resilience on the association between emotional neglect and depressive symptoms. Psychiatry Investigation. https://doi.org/10.4306/pi.2018.15.1.62 
Liang, D., Xu, D., Xia, L., \& Ma, X. (2020). Life satisfaction in Chinese rural-to-urban migrants: Investigating the roles of self-esteem and affect balance. Journal of Community Psychology. doi.org/10.1002/jcop.22360

Liu, Y., Wang, Z., \& Lü, W. (2013). Resilience and affect balance as mediators between trait emotional intelligence and life satisfaction. Personality and Individual Differences, 54(7), 850-855.

Loh, J. M. I., Schutte, N. S., \& Thorsteinsson, E. B. (2014). Be happy: The role of resilience between characteristic affect and symptoms of depression. Journal of Happiness Studies. https://doi.org/10.1007/s10902-013-9467-2

Luthar, S. S. (Ed.). (2003). Resilience and vulnerability: Adaptation in the context of childhood adversities. New York: Cambridge University Press.

Luthar, S. S., Cicchetti, D., \& Becker, B. (2000). The construct of resilience: A critical evaluation and guidelines for future work. Child Development, 71, 543-562.

Mascaro, N., \& Rosen, D. H. (2005). Existential meaning's role in the enhancement of hope and prevention of depressive symptoms. Journal of Personality, 73(4), 985-1014.

Moon, H. I., Yoon, S. Y., Jeong, Y. J., \& Cho, T. H. (2018). Sleep disturbances negatively affect balance and gait function in post-stroke patients. NeuroRehabilitation, 43(2), 211-218.

Oliver, K. G., Collin, P., Burns, J., \& Nicholas, J. (2006). Building resilience in young people through meaningful participation. Australian e-Journal for the advancement of Mental Health, 5(1), 34-40.

Ong, A. D., Bergeman, C. S., Bisconti, T. L., \& Wallace, K. A. (2006). Psychological resilience, positive emotions, and successful adaptation to stress in later life. Journal of Personality and Social Psychology, 91(4), 730-749. 
Pan, J.-Y., Wong, D. F. K., Chan, C. L. W., \& Joubert, L. (2008). Meaning of life as a protective factor of positive affect in acculturation: A resilience framework and a cross-cultural comparison. International Journal of Intercultural Relations, 32(6), 505-514. https://doi.org/10.1016/j.ijintrel.2008.08.002

Pieruccini-Faria, F., Muir-Hunter, S. W., \& Montero-Odasso, M. (2018). Do depressive symptoms affect balance in older adults with mild cognitive impairment? Results from the "gait and brain study". Experimental Gerontology, 108, 106-111.

Preacher, K. J., \& Hayes, A. F. (2008). Asymptotic and resampling strategies for assessing and comparing indirect effects in multiple mediator models. Behavior Research Methods, 40(3), 879-891.

Schlegel, R. J., Hicks, J. A., King, L. A., \& Arndt, J. (2011). Feel-ing like you know who you are: Perceived true self-knowledge and meaning in life. Personality and Social Psychology Bulletin,37(6), 745---756.

Shi, M., Wang, X., Bian, Y., \& Wang, L. (2015). The mediating role of resilience in the relationship between stress and life satisfaction among Chinese medical students: a cross-sectional study. BMC Medical Education, 15(1), 16. https://doi.org/10.1186/s12909-015-0297-2

Smith, B. W., Dalen, J., Wiggins, K., Tooley, E., Christopher, P., \& Bernard, J. (2008). The brief resilience scale: Assessing the ability to bounce back. International Journal of Behavioral Medicine, 15(3), 194-200. doi: 10.1080/10705500802222972

Steger, M. F., Frazier, P., Oishi, S., \& Kaler, M. (2006). The meaning in life questionnaire: Assessing the presence of and search for meaning in life. Journal of Counseling Psychology, 53(1), 80-93. https://doi.org/10.1037/0022-0167.53.1.80

Steger, M. F., Mann, J. R., Michels, P., \& Cooper, T. C. (2009). Meaning in life, anxiety, depression, and general health among smoking cessation patients. Journal of 
Psychosomatic Research, 67(4), 353-358.

https://doi.org/10.1016/j.jpsychores.2009.02.006

Steger, M. F., Oishi, S., \& Kashdan, T. B. (2009). Meaning in life across the life span: Levels and correlates of meaning in life from emerging adulthood to older adulthood. The Journal of Positive Psychology, 4(1), 43-52.

https://doi.org/10.1080/17439760802303127

Stevens, J. P. (2009). Applied multivariate statistics for the social sciences. New York: Routledge.

Strand, E. B., Zautra, A. J., Thoresen, M., Ødegård, S., Uhlig, T., \& Finset, A. (2006). Positive affect as a factor of resilience in the pain-negative affect relationship in patients with rheumatoid arthritis. Journal of Psychosomatic Research, 60(5), 477484. https://doi.org/10.1016/j.jpsychores.2005.08.010

Tabachnick, B. G., \& Fidell, L. S. (2013). Using multivariate statistics (6th ed.). Boston, MA: Pearson.

Tecson, K. M., Wilkinson, L. R., Smith, B., \& Ko, J. M. (2019). Association between psychological resilience and subjective well-being in older adults living with chronic illness. In Baylor University Medical Center Proceedings (Vol. 32, No. 4, pp. 520524). Taylor \& Francis.

Tedeschi, R. G., \& Kilmer, R. P. (2005). Assessing strengths, resilience, and growth to guide clinical interventions. Professional Psychology: Research and Practice, 36(3), 230237.

Telef, B. (2013). The Scale of Positive and Negative Experience: a validity and reliability study for adolescents. Anatolian Journal of Psychiatry, 14(1), 62. doi: 10.5455/apd.36692 
Tugade, M. M., \& Fredrickson, B. L. (2004). Resilient Individuals Use Positive Emotions to Bounce Back from Negative Emotional Experiences. Journal of Personality and Social Psychology, 86(2), 320-333. https://doi.org/10.1037/0022-3514.86.2.320

Veilleux, J. C., Lankford, N. M., Hill, M. A., Skinner, K. D., Chamberlain, K. D., Baker, D. E., \& Pollert, G. A. (2020). Affect balance predicts daily emotional experience. Personality and Individual Differences, 154, 109683.

Veronese, G., Pepe, A., Dagdukee, J., \& Yaghi, S. (2018). Social capital, affect balance, and personal well-being among teachers in Israel and Palestine. Teachers and Teaching, 24(8), 951-964.

Watson, D., Clark, L. A., \& Tellegen, A. (1988). Development and validation of brief measures of positive and negative affect: the PANAS scales. Journal of Personality and Social Psychology, 54(6), 1063-1070. doi: 10.1037//0022-3514.54.6.1063

Weissman, J. S., Pratt, L. A., Miller, E. A., \& Parker, J. D. (2015). Serious Psychological Distress Among Adults, United States, 2009-2013. US Department of Health and Human Services, Centers for Disease Control and Prevention, National Center for Health Statistics.

Wong, P. T. (2011). Positive psychology 2.0: Towards a balanced interactive model of the good life. Canadian Psychology/Psychologie Canadienne, 52(2), 69.

Wong, P. T. P. (1998). Meaning-centered counselling. In P. T. P. Wong \& P. S. Fry (Eds.), The human quest for meaning: A handbook of psychological research and clinical application (pp.395-435). Mahwah, NJ: Lawrence Erlbaum Associates.

Wong, P. T. P. (2010). Meaning therapy: An integrative and positive existential psychotherapy. Journal of Contemporary Psychotherapy, 40(2), 85-93.

Wong, P. T. (2019). Second wave positive psychology's (PP 2.0) contribution to counselling psychology. Counselling Psychology Quarterly, 32(3-4), 275-284. 
Wong, P. T. P. (2012). The human quest for meaning: Theories, research, and applications. New York, NY: Routledge.

Wong, P. T. P. (2016). Meaning centered positive group intervention. In P. Russo-Netzer, S. Schulenberg, \& A. Batthyány (Eds.), Clinical perspectives on meaning: Positive and existential psychotherapy (pp. 423-445). New York, NY: Springer.

Wong, P. T. P., \& McDonald, M. (2002). Tragic optimism and personal meaning in counselling victims of abuse. Pastoral Sciences, 20(2), 231-249.

Wong, P. T. P., \& Wong, L. C. J. (2012). A meaning-centered approach to building youth resilience. In The human quest for meaning: Theories, research, and applications, 2nd ed. (pp. 585-617). Routledge/Taylor \& Francis Group.

World Health Organization. (2020a). WHO timeline - COVID-19. Retrieved from https://www.who.int/news-room/detail/08-04-2020-who-timeline---covid-19

World Health Organization. (2020b). Mental health and psychosocial considerations during the COVID-19 outbreak. Retrieved from https://www.who.int/docs/defaultsource/coronaviruse/mental-health-considerations.pdf?sfvrsn=6d3578af_2

Wu, F., Zhao, S., Yu, B., Chen, Y. M., Wang, W., Song, Z. G., ... \& Yuan, M. L. (2020). A new coronavirus associated with human respiratory disease in China. Nature, 579(7798), 265-269.

Xie, L., Zhou, J., Deng, Y., Richmond, C. J., \& Na, J. (2019). Resilience and affect balance of empty-nest older adults with mild cognitive impairment in poor rural areas of Hunan province, China. Geriatrics \& Gerontology International, 19(3), 222-227.

Yalçın, İ., \& Malkoç, A. (2015). The Relationship Between Meaning in Life and Subjective Well-Being: Forgiveness and Hope as Mediators. Journal of Happiness Studies, 16(4), 915-929. https://doi.org/10.1007/s10902-014-9540-5 
Yang, Y., Li, W., Zhang, Q., Zhang, L., Cheung, T., \& Xiang, Y. T. (2020). Mental health services for older adults in China during the COVID-19 outbreak. The Lancet Psychiatry, 7(4), e19. https://doi.org/10.1016/S2215-0366(20)30079-1

Yıldırım, M. (2019). Irrational Happiness Beliefs: Conceptualization, Measurement and Its Relationship with Well-being, Personality, Coping Strategies, and Arousal, (Unpublished Doctoral Dissertation). University of Leicester, Leicester, UK

Yildirim, M. (2019). Mediating role of resilience in the relationships between fear of happiness and affect balance, satisfaction with life, and flourishing. Europe's Journal of Psychology, 15(2), 183-198.

Yildirim, M., \& Arslan, G. (2020). Exploring the associations between resilience, dispositional hope, subjective well-being, and psychological health among adults during early stage of COVID-19. Doi: 10.31234/osf.io/vpu5q

Zhang, J., Lu, H., Zeng, H., Zhang, S., Du, Q., Jiang, T., \& Du, B. (2020). The differential psychological distress of populations affected by the COVID-19 pandemic. Brain, Behavior, and Immunity.

Zhou, P., Yang, X. L., Wang, X. G., Hu, B., Zhang, L., Zhang, W., ... \& Chen, H. D. (2020). A pneumonia outbreak associated with a new coronavirus of probable bat origin. Nature, 579(7798), 270-273. 
Table 1.

Descriptive statistics and correlation results $(N=359)$

\begin{tabular}{lcccccccccc}
\hline Scales & $M$ & $S D$ & Skew. & Kurt. & $\alpha$ & 1. & 2. & 3. & 4. & 5. \\
\hline 1. Meaningful living & 33.95 & 5.62 & -1.14 & -1.44 & .80 & - & $.41^{* *}$ & $-.22^{* *}$ & $.29^{* *}$ & $-.42^{* *}$ \\
2. Positive affect & 20.14 & 4.33 & -.34 & .13 & .90 & - & -.33 & .37 & -.35 \\
3. Negative affect & 16.15 & 3.57 & -.09 & -.06 & .77 & & - & -.35 & .43 \\
4. Resilience & 18.13 & 5.42 & .01 & -.17 & .86 & & & - & -.38 \\
5. Psychological health & 20.75 & 13.19 & .73 & .01 & .92 & & & & - \\
\hline
\end{tabular}

Note. ${ }^{* *}$ Correlation is significant at the .001 level (2-tailed). 
Table 2.

Unstandardized coefficients for the mediation model

\begin{tabular}{|c|c|c|c|c|c|c|c|c|c|c|c|c|c|c|c|c|}
\hline \multirow[b]{3}{*}{ Antecedent } & \multicolumn{16}{|c|}{ Consequent } \\
\hline & \multicolumn{4}{|c|}{$M_{l}$ (Positive Affect) } & \multicolumn{4}{|c|}{$M_{2}$ (Negative Affect) } & \multicolumn{4}{|c|}{$M_{3}($ Resilience $)$} & \multicolumn{4}{|c|}{$Y$ (Psychological health) } \\
\hline & Coeff. & $S E$ & $t$ & $p$ & Coeff. & $S E$ & $t$ & $p$ & Coeff. & $S E$ & $t$ & $p$ & Coeff. & $S E$ & $t$ & $p$ \\
\hline$X$ (Meaning) & .31 & .03 & 8.47 & $<.001$ & -.14 & .03 & -4.13 & $<.001$ & .14 & .05 & 2.86 & .004 & -.64 & .11 & -5.74 & $<.001$ \\
\hline$M_{1}$ (Positive) & - & - & - & - & - & - & - & - & .28 & .07 & 4.18 & $<.001$ & -.23 & .15 & -1.49 & .135 \\
\hline$M_{2}$ (Negative) & - & - & - & - & - & - & - & - & -.37 & .08 & -4.88 & $<.001$ & .96 & .17 & 5.53 & $<.001$ \\
\hline$M_{3}$ (Resilience) & - & - & - & - & - & - & - & - & - & - & - & - & -.40 & .12 & -3.41 & $<.001$ \\
\hline \multirow[t]{2}{*}{ Constant } & 9.51 & 1.27 & 7.47 & $<.001$ & 20.71 & 1.11 & 18.50 & $<.001$ & 13.64 & 2.43 & 5.60 & $<.001$ & 38.64 & 5.57 & 6.92 & $<.001$ \\
\hline & \multicolumn{4}{|c|}{$R^{2}=.17$} & \multicolumn{4}{|c|}{$R^{2}=.05$} & \multicolumn{4}{|c|}{$R^{2}=.21$} & \multicolumn{4}{|c|}{$R^{2}=.32$} \\
\hline
\end{tabular}

Note. $S E=$ standard error. Coeff $=$ unstandardized coefficient. $X=$ independent variable; $M=$ mediator variables; $Y=$ outcomes or dependent variables 
Table 3

Unstandardized total, direct and indirect effects, and 95\% bias-corrected confidence interval predicting psychological health scores

\begin{tabular}{lcccc}
\hline Path & Effect & SE & BootLLCI & BootULCI \\
\hline Total effect & -.95 & .11 & -1.16 & -.74 \\
Direct effect & -.63 & .10 & -.85 & -.41 \\
Total indirect effect & -.31 & .07 & -.46 & -.18 \\
$\quad$ Meaning-> Positive->Psychological health & -.07 & .05 & -.18 & .03 \\
Meaning-> Negative->Psychological health & -.12 & .05 & -.23 & -.07 \\
Meaning-> Resilience->Psychological health & -.05 & .03 & -.13 & -01 \\
Meaning->Positive-> Resilience->Psychological health & -.04 & .02 & -.07 & -.01 \\
Meaning-> Negative-> Resilience->Psychological health & -.02 & .01 & -.04 & -.01 \\
\hline
\end{tabular}

Note. Number of bootstrap samples for percentile bootstrap confidence intervals: 10000 


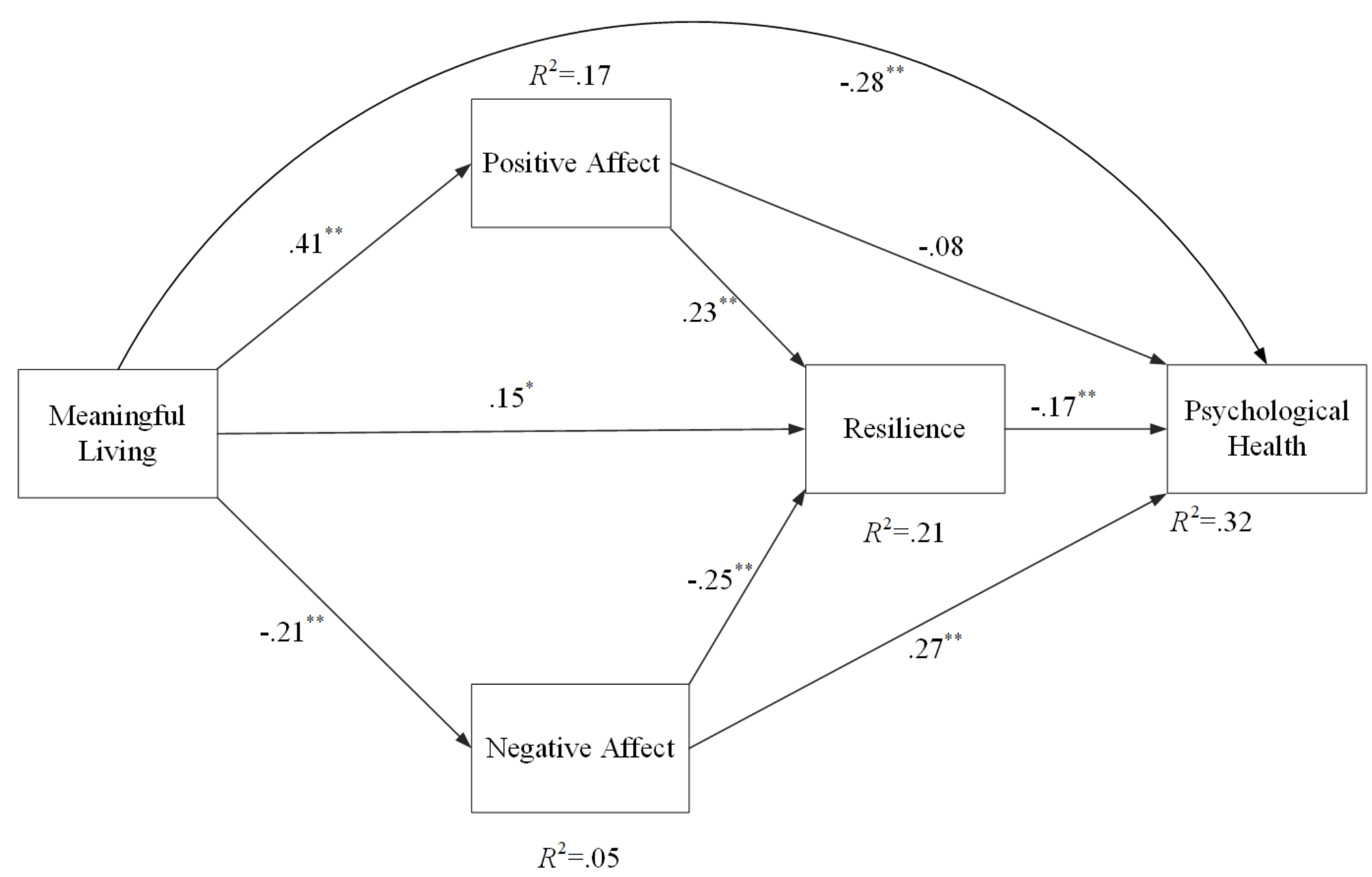

Figure 1. Structural model demonstrating the association between the variables of study 